\title{
SEBUAH ALTERNATIF: INDEKS STUNTING SEBAGAI EVALUASI KEBIJAKAN INTERVENSI BALITA STUNTING DI INDONESIA
}

\section{An Alternative: Stunting Index as Policy Evaluation of Stunting Intervention of Children Under-5 Years in Indonesia}

\author{
Zenderi Wardani ${ }^{1,2}$, Dadang Sukandar ${ }^{2}$, Yayuk Farida Baliwati², Hadi Riyadi² \\ 1Jurusan Gizi, Politeknik Kesehatan Kemenkes Pangkalpinang \\ 2Departemen Gizi Masyarakat, Fakultas Ekologi Manusia - IPB University \\ E-mail: zenderi.w@gmail.com
}

\section{ABSTRACT}

The proportion of stunting above 20 percent indicates that there are still public health problems in Indonesia. The impact of stunting not only affects the stature but also affects the economic productivity of a country. The purpose of this study was to develop index models that are responsive stunting in children under-5 years in Indonesia. Development of the index model used mathematical formulations using the SDGs indicator and other relevant indicators. Aggregate data from 16-time series were selected from 34 provinces in Indonesia in the span of 4 years (2015 - 2018). Furthermore, the method of developing a stunting index in this study was carried out through the stages of standardization, weighting, aggregation and validation. The results showed that the stunting index model is an evaluation measure that is responsive to stunting interventions in infants (0-56 months) in Indonesia. The national stunting index from 2015 to 2018 increased although it was still in the medium category with index values of $69.77,70.29$, 70.30 and 72.74 , respectively. This study recommended an increase in efforts to achieve dimension index values in the development pillars of environmental and economical, especially in the eastern regions of Indonesia and the divided provinces.

Keywords: stunting index, policy evaluation, children under five

\section{ABSTRAK}

Proporsi stunting lebih dari 20 persen menunjukkan bahwa masih terdapat masalah kesehatan masyarakat di Indonesia. Dampak stunting tidak hanya mempengaruhi perawakan tetapi juga mempengaruhi produktifitas ekonomi suatu negara. Sebuah model sederhana dan responsif dalam bentuk indeks stunting dapat menjadi bagian dari pilar rencana aksi intervensi stunting tersebut di atas. Model indeks stunting pun diharapkan dapat membantu pengambil keputusan (decision maker) menyusun formulasi, implementasi dan evaluasi kebijakan dalam penanggulangan stunting untuk masa yang akan datang. Tujuan penelitian ini adalah untuk mengembangkan model indeks stunting responsif pada anak balita di Indonesia. Pengembangan model indeks menggunakan formulasi matematis dengan menggunakan indikator Sustainable Development Goals (SDGs) dan indikator terkait lainnya. Data agregat dari 16 time series dipilih dari 34 provinsi di Indonesia dalam kurun waktu 4 tahun (2015 - 2018). Selanjutnya metode pengembangan indeks stunting pada penelitian ini dilakukan melalui tahapan standardisasi, pembobotan, agregasi dan validasi. Hasil penelitian menunjukkan bahwa model indeks stunting pada penilitian ini merupakan ukuran evaluasi yang tanggap terhadap intervensi stunting pada bayi (0-56 bulan) di Indonesia. Indeks stunting nasional dari tahun 2015 sampai 2018 mengalami peningkatan meskipun masih dalam kategori sedang dengan nilai indeks masing-masing 69,77, 70,29, 70,30 dan 72,74 . Studi ini merekomendasikan peningkatan upaya pencapaian nilai indeks dimensi pada pilar pembangunan lingkungan dan ekonomi khususnya di wilayah timur Indonesia dan daerah provinsi pemekaran.

Kata kunci: Indeks stunting, evaluasi kebijakan, anak balita

Doi: $10.36457 / g i z i n d o . v 44 i 1.535$

www.persagi.org/ejournal/index.php/Gizi_Indon 


\section{PENDAHULUAN}

D ampak yang terjadi pada anak-anak yang mengalami stunted menjadikan komposisi tubuh mereka lebih rendah terutama ukuran otot lengan sehingga menghambat perkembangan motorik anak 1,2 kegagalan pertumbuhan fisik dan kerusakan neurokognitif3. Selain pada perawakan seseorang bahwa stunting juga berpengaruh pada kognitif dan pendidikan yang rendah pada saat usia sekolah2,4,5. Stunted pada saat dewasa menyebabkan kinerja dan pengeluaran rumah tangga per kapita yang lebih rendah dan sebagian besar hidup dalam kemiskinan karena biaya perawatan kesehatan dan masalah sosial6.

Global Nutrition Report pada tahun 2020 melaporkan ada sekitar 149 juta atau sekitar 21,9 persen balita mengalami stunting di seluruh dunia dan sebagian besar berada di wilayah Asia yaitu 81,7 juta balita atau 54,8 persen. World Health Organization (WHO) menetapkan target penurunan stunting sebesar 40 persen pada tahun $2025^{7}$. Perhitungan Bank Dunia menunjukkan bahwa pendapatan per kapita penduduk lebih rendah 7 persen daripada seharusnya jika tidak ada intervensi untuk mengurangi stunting suatu negara. Negara- negara Afrika dan Asia Tenggara bahkan cenderung lebih tinggi yaitu sekitar 9-10 persen dari Produk Domestik Bruto (PDB) per kapita ${ }^{8}$.

Hasil Riset Kesehatan Dasar (Riskesdas) menunjukkan kondisi sebaliknya. Proporsi balita pendek di Indonesia mulai dari tahun 2007 sampai dengan 2013 tidak terjadi penurunan yang bermakna. Proporsi stunting pada tahun 2007 sebesar 37,6 persen menurun pada tahun 2010 menjadi 35,8 persen, kemudian meningkat sebesar 37,2 persen pada tahun $2013^{9}$, dan kembali menurun menjadi 30,8 persen pada tahun $2018^{10}$. Kenaikan proporsi stunting bahkan terjadi pada anak usia di bawah dua tahun (baduta) dari 28,0 persen pada tahun 2013 menjadi 29,9 persen pada tahun 2018. ${ }^{10}$ Kondisi kekurangan gizi di Indonesia sendiri menyebabkan hilangnya potensi ekonomi sebesar 0,04-0,16 persen dari total PDB untuk stunting. ${ }^{11}$

Kondisi proporsi stunting baduta maupun balita yang masih berada di atas 20 persen yang terjadi di suatu wilayah mengindikasikan bahwa masih terjadinya masalah gizi kronis dan masalah kesehatan masyarakat (public health problem). Upaya intervensi gizi spesifik dan sensitif stunting pada awalnya merupakan bagian dari Gerakan Nasional Sadar Gizi dalam rangka 1000 Hari Pertama Kehidupan (HPK) telah dilakukan pemerintah. Berbagai hambatan dalam pelaksanaan intervensi mendorong pemerintah menetapkan langkah-langkah terobosan dan percepatan program. Rekomendasi rencana aksi intervensi stunting disusun kembali dengan salah satu pilar utama adalah pemantauan dan evaluasi secara berkala. Pilar utama tersebut memastikan kualitas layanan program intervensi stunting dan result-based planning and budgeting (penganggaran dan perencanaan berbasis hasil) pada tingkat pusat dan daerah, serta pengendalian program intervensi ${ }^{12}$.

Sebuah model sederhana dan responsif dalam bentuk indeks stunting dapat menjadi bagian dari pilar rencana aksi intervensi stunting tersebut di atas. Model indeks stunting pun diharapkan dapat membantu pengambil keputusan (decision maker) menyusun formulasi, implementasi dan evaluasi kebijakan dalam penanggulangan stunting untuk masa yang akan datang. Tujuan penelitian ini adalah mengembangkan model indeks stunting yang responsif terhadap anak usia balita (0-59 bulan) di Indonesia.

\section{METODE PENELITIAN}

Penelitian ini dilakukan pada bulan Mei sampai dengan Juni 2019 di Departemen Gizi Masyarakat, Fakultas Ekologi Manusia, IPB University - Bogor dan merupakan bagian dari disertasi yang telah mendapatkan persetujuan Komisi Etik Penelitian LPPM - IPB University Nomor 217/IT3.KEPMSM-IPB/SK/2019. Pengembangan model indeks stunting menggunakan formulasi matematis terhadap data sekunder dari metadata indikator Sustainable Development Goals/ Tujuan Pembangunan Berkelanjutan (SDGs/TPB) yang terdiri dari 4 pilar pembangunan yaitu sosial, ekonomi, lingkungan, serta hukum dan tata kelola ${ }^{13}$. Metadata indikator SDGs/ TPB merupakan salah satu cara mengukur pencapaian pembangunan berkelanjutan di Indonesia melalui evaluasi perkembangan program-program pembangunan yang telah 
dilaksanakan. Program penanggulangan stunting adalah salah satu program yang dapat dievaluasi melalui metadata indikator tersebut. Indikator yang akan dianalisis merupakan rangkaian data deret waktu (time series) dalam rentang waktu 4 tahun (2015-2018) yang dipilih berdasarkan telaah literatur terkait stunting di Indonesia sejak 17 tahun terakhir ${ }^{14}$ dan strategi nasional percepatan pencegahan stunting ${ }^{12}$, serta harga pangan. ${ }^{15}$ Berdasarkan telaah tersebut dan ketersediaan data yang bersumber dari Badan Pusat Statistik, Kementerian Kesehatan, Kementerian Pertanian dan Kementerian Pekerjaan Umum dan Perumahan Rakyat Republik Indonesia maka ditetapkan 16 indikator sebagai variabel bebas $\left(X_{i}\right)$ dari 34 provinsi di Indonesia.

Metode penyusunan indeks stunting pada penelitian ini dilakukan melalui tahapan standarisasi, pembobotan, agregasi dan validasi. Tahapan pertama yaitu standarisasi dilakukan pada data yang memiliki unit pengukuran yang berbeda. Penelitian ini menggunakan standarisasi dengan pendekatan maksimum-minimun. Variabel yang dipilih terlebih dahulu dibuat sedemikian rupa agar mempunyai arah yang sama yaitu arah positif (semakin besar nilai akan semakin baik) dan selanjutnya ditransformasikan dalam skor 0 100. Adapun pendekatan ini menggunakan formulasi:

$$
J_{\text {in }}=\frac{x_{i n}-x_{\text {min }}}{x_{\max }-x_{\min }} \times 100
$$

Dalam hal ini $x_{\min }$ adalah nilai minimum dari variabel tertentu; $x_{\max }$ adalah nilai minimum dari variabel tertentu; dan $x_{i n}$ adalah nilai variabel pada suatu observasi. Nilai minimum dan maksimum variabel yang digunakan pada penelitian ini secara ringkas dapat dilihat pada Tabel 1.

Tabel 1

Nilai Minimum dan Maksimum Variabel Pemodelan Indeks Stunting

\begin{tabular}{|c|c|c|c|}
\hline No & Variabel & Min. & Maks. \\
\hline \multicolumn{4}{|c|}{ Pilar Pembangunan Sosial } \\
\hline 1. & Skor Pola Pangan Harapan/ PPH $\left(X_{1}\right)$ & 68,00 & 96,50 \\
\hline 2. & Asupan energi min. penduduk $>1400 \mathrm{kkal} /$ kapita/hari $\left(X_{2}\right)$ & 67,41 & 97,85 \\
\hline 3. & Bayi usia $<6$ bulan yang mendapatkan ASI eksklusif $\left(X_{3}\right)$ & 21,27 & 78,28 \\
\hline 4. & Peserta jaminan kesehatan $\left(X_{4}\right)$ & 40,19 & 100 \\
\hline 5. & Angka melek aksara penduduk usia $\geq 15$ tahun $\left(X_{5}\right)$ & 70,83 & 99,87 \\
\hline 6. & Anak $12-23$ bulan dengan imunisasi dasar lengkap $\left(X_{6}\right)$ & 29,60 & 100 \\
\hline 7. & Angka bebas API malaria per 1000 penduduk $\left(\mathcal{X}_{7}\right)$ & 41,00 & 100 \\
\hline 8. & Kebiasaan tidak merokok penduduk usia $\geq 15$ tahun $\left(X_{8}\right)$ & 63,44 & 78,38 \\
\hline \multicolumn{4}{|c|}{ Pilar Pembangunan Ekonomi } \\
\hline 9. & Laju pertumbuhan PDB per kapita $\left(\mathcal{X}_{9}\right)$ & $-5,67$ & 20,20 \\
\hline 10. & Penduduk yang hidup di atas garis kemiskinan $\left(x_{10}\right)$ & 71,46 & 96,43 \\
\hline 11. & Kondisi mantap jalan nasional $\left(X_{11}\right)$ & 67,23 & 99,95 \\
\hline 12. & Skor harga rata-rata beras $\left(x_{12}\right)$ & 22,54 & 73,60 \\
\hline 13. & Skor harga rata-rata telur $\left(x_{13}\right)$ & 17,48 & 62,82 \\
\hline \multicolumn{4}{|c|}{ Pilar Pembangunan Lingkungan } \\
\hline 14. & RT yang memiliki akses air minum layak $\left(x_{14}\right)$ & 37,35 & 93,40 \\
\hline 15. & RT yang memiliki akses sanitasi layak $\left(\mathcal{X}_{15}\right)$ & 23,37 & 91,14 \\
\hline \multicolumn{4}{|c|}{ Pilar Pembangunan Hukum \& Tata Kelola } \\
\hline & Anak yang memiliki akta kelahiran $\left(X_{16}\right)$ & 36,32 & 97,40 \\
\hline
\end{tabular}


Tabel 2

Matriks Korelasi antar-Variabel $X_{1}$

\begin{tabular}{cccccc}
\hline Nilai absolut korelasi & $x_{1}$ & $x_{2}$ & $\ldots$ & $x_{p}$ & Jumlah \\
\hline$x_{1}$ & 1 & $x_{12}$ & $\ldots$ & $x_{1 p}$ & $\mathcal{T}_{1}$ \\
$x_{2}$ & $x_{21}$ & 1 & $\ldots$ & $x_{2 p}$ & $\mathcal{T}_{2}$ \\
$\vdots$ & $\vdots$ & $\vdots$ & $\vdots$ & $\vdots$ & $\vdots$ \\
$x_{p}$ & $x_{p 1}$ & $x_{p 2}$ & $\ldots$ & 1 & $\mathcal{T}_{p}$ \\
Jumlah & $\mathcal{T}_{1}$ & $\mathcal{T}_{2}$ & $\ldots$ & $\mathcal{T}_{p}$ & $\mathcal{T}$ \\
\hline
\end{tabular}

Tahapan kedua adalah pembobotan menggunakan analisis korelasi atau matriks korelasi. Penimbang yang ditentukan berdasarkan pada matriks korelasi diasumsikan proporsional (sebanding) dengan nilai absolut koefesien korelasi pada masing-masing baris dan kolom. Penimbang setiap variabel ditentukan dengan menghitung proporsi dari jumlah setiap baris/ kolom terhadap jumlah keseluruhan. Asumsi logis yang mendasari bahwa sebuah variabel yang lebih penting akan memiliki jumlah koefesien korelasi lebih besar ${ }^{16}$. Tabel 2 berikut ini merupakan contoh penimbang variabel $X_{1}$ dalam matriks korelasi. Penimbang untuk variabel $\mathcal{X}_{1}$ adalah $\mathcal{W}_{1}=\mathcal{T}_{1}$ $/ \mathcal{T}$. Cara yang sama dilakukan untuk mendapatkan peimbang variabel lainnya.

Tahapan ketiga adalah agregasi untuk mendapatkan indeks komposit sehingga didapatkan nilai akhir suatu indeks. Metode agregasi linear digunakan pada penelitian ini dengan cara menjumlahkan pembobot dan nilai variabel yang telah distandarisasi, dengan rumus:

$$
\mathcal{J S}=\sum_{i=1}^{p} \mathcal{W}_{i} \mathcal{J}_{i}
$$

Dalam hal ini $\mathcal{J S}$ adalah indeks stunting; $p$ adalah banyaknya variabel; $\mathcal{W}_{i}$ adalah penimbang variabel ke-i; dan $J_{i}$ adalah nilai variabel ke-i yang sudah distandarisasi. Kategori $\mathcal{J} \mathcal{S}$ provinsi disusun menggunakan nilai kuartil indeks pada tiap tahunnya. Distribusi data nilai $\mathcal{J S}$ yang tidak normal merupakan alasan pemilihan metode tersebut karena tidak memungkinkan membuat kategori berdasarkan sebaran data terhadap rata-rata. Pengelompokan provinsi dibagi dalam tiga kategori, yaitu di atas kuartil atas (Q3), di bawah kuartil bawah (Q1), dan antara kuartil atas dan kuratil bawah. Notasi kategori provinsi disajikan berikut ini: (a) $\mathcal{J} \mathcal{S}>Q_{3 t}=$ Tinggi; (b) $Q_{1 \mathrm{t}} \leq \mathcal{J} \mathcal{S} \leq$ $\mathrm{Q}_{3 \mathrm{t}}=$ Sedang; dan (c) $\mathcal{J} \mathcal{S}<\mathrm{Q}_{1 \mathrm{t}}=$ Rendah. Nilai $\mathcal{J S}$ provinsi yang berada pada katagori rendah akan memiliki potensi terjadinya stunting semakin tinggi sehingga membutuhkan prioritas untuk ditanggulangi. Semakin tinggi nilai $\mathcal{J} \mathcal{S}$ provinsi maka semakin baik konvergensi dan koordinasi penanggulangan stunting di daerah tersebut.

Tahap keempat adalah validasi terhadap indeks stunting yang dilakukan dengan analisis korelasi Pearson terhadap prevalensi stunting balita 0 - 59 bulan pada tahun 2018 menggunaan persamaan:

$$
r=\frac{n \sum x_{i} y_{i}-\sum x_{i} \sum y_{i}}{\sqrt{n \sum x_{i}^{2}-\left(\sum x_{i}\right)^{2}} \sqrt{n \sum y_{i}^{2}-\left(\sum y_{i}\right)^{2}}}
$$

Hasil validasi kemudian dinyatakan dalam bentuk: $\mathrm{H}_{0}: \rho=0$ dan $\mathrm{H}_{\mathrm{i}}: \rho \neq 0$

\section{HASIL}

Hasil analisis matriks korelasi terhadap 16 variabel (Tabel 3) menunjukkan bahwa setiap variabel mempunyai bobot yang bervariasi, meskipun masing-masing variabel tidak menunjukkan perubahan yang berarti setiap tahunnya. Hal ini memberikan informasi bahwa dalam proses intervensi stunting hendaknya mempertimbangkan variabel yang mempunyai prioritas yang lebih besar. Tabel tersebut juga menjelaskan bahwa prioritas setiap variabel dapat dibandingkan terhadap jumlah penimbang dalam dimensi yang sama. Penimbang variabel skor PPH terhadap pilar pembangunan sosial tahun 2015 sebagai contoh yaitu $0,037 /(0,037+0,087+0,017+(-$ $0,002)+0,051+0,106+0,094+0,016)=0,091$. 
Langkah ini dapat dilakukan untuk memperoleh indeks stunting per dimensi.

Tahapan agregasi dari dimensi yang terdiri dari 4 pilar pembangunan kemudian menghasilkan nilai $\mathcal{J} \mathcal{S}$ komposit nasional tahun 2015 - 2018 seperti ditampilkan pada Tabel 4. Nilai indeks stunting mengalami peningkatan setiap tahunnya. Nilai $\mathcal{J} \mathcal{S}$ pada dimensi pilar pembangunan lingkungan merupakan nilai pencapaian paling rendah dan diikuti oleh dimensi pilar pembangunan ekonomi selama periode tahun penilaian. Pada tahun 2017, kedua nilai IS dimensi tersebut mengalami penurunan masing-masing sekitar 1 poin.

Pengelompokan secara relatif terhadap nilai $\mathcal{J} \mathcal{S}$ komposit untuk membandingkan nilai indeks antar-wilayah dan juga membandingkan nilai indeks antar-waktu. Nilai $\mathcal{J} \mathcal{S}$ dan kategori nilai masing-masing provinsi dan nasional dapat dilihat pada Tabel 5 . Jumlah provinsi berdasarkan kategori nilai $\mathcal{J} \mathcal{S}$ mengalami fluktuasi dan jumlah provinsi dengan kategori $\mathcal{J S}$ rendah terbanyak terjadi pada tahun 2015 dan 2017 sebanyak masing-masing 9 provinsi. Provinsi Papua merupakan daerah dengan nilai paling rendah setiap tahun penilian, diikuti oleh Nusa Tenggara Timur dan Papua Barat. Nilai $\mathcal{J S}$ tertinggi berturut-turut setiap tahun dimiliki oleh Provinsi Bali yang diikuti oleh Jakarta dan Yogyakarta.

Hasil validasi menggunakan analisis korelasi antara nilai $\mathcal{J} \mathcal{S}(2015-2018)$ terhadap prevalensi stunting pada tahun 2018 dapat dilihat dalam Tabel 6 . Hasil validasi nilai $\mathcal{J} \mathcal{S}$ menghasilkan kekuatan yang bermakna setiap tahun penilaian dengan nilai validasi dan kemaknaan paling tinggi terjadi pada tahun 2016.

Tabel 3

Penimbang Setiap Variabel Pemodelan Indeks Stunting

\begin{tabular}{ccccc}
\hline Variabel & \multicolumn{4}{c}{ Weight $(\mathcal{W})$} \\
\hline$x_{1}$ & 0,037 & 2016 & 2017 & 2018 \\
$x_{2}$ & 0,087 & 0,057 & 0,034 & 0,039 \\
$x_{3}$ & 0,017 & 0,008 & 0,088 & 0,089 \\
$x_{4}$ & $-0,002$ & $-0,004$ & 0,006 & 0,002 \\
$x_{5}$ & 0,051 & 0,050 & 0,014 & 0,042 \\
$x_{6}$ & 0,106 & 0,096 & 0,064 & 0,060 \\
$x_{7}$ & 0,094 & 0,085 & 0,072 & 0,091 \\
$x_{8}$ & 0,016 & 0,030 & 0,094 & 0,100 \\
$x_{9}$ & 0,025 & 0,008 & 0,030 & 0,032 \\
$x_{10}$ & 0,074 & 0,075 & 0,036 & 0,006 \\
$x_{11}$ & 0,069 & 0,086 & 0,083 & 0,085 \\
$x_{12}$ & 0,075 & 0,077 & 0,074 & 0,054 \\
$x_{13}$ & 0,082 & 0,089 & 0,073 & 0,048 \\
$x_{14}$ & 0,076 & 0,069 & 0,083 & 0,075 \\
$x_{15}$ & 0,097 & 0,099 & 0,059 & 0,068 \\
$x_{16}$ & 0,094 & 0,096 & 0,091 & 0,096 \\
\hline
\end{tabular}


Tabel 4

Nilai Indeks Stunting Indonesia Berdasarkan Dimensi

\begin{tabular}{cccccc}
\hline \multirow{2}{*}{ Tahun } & \multicolumn{4}{c}{ Nilai $\mathcal{J} \mathcal{S}$ dimensi } & \multirow{2}{*}{$\begin{array}{c}\text { Nilai } \mathcal{J} \mathcal{S} \\
\text { komposit }\end{array}$} \\
\cline { 2 - 4 } & PPS & PPE & PPL & PPHTK & kom, \\
\hline 2015 & 77,37 & 65,83 & 58,04 & 72,01 & 69,77 \\
2016 & 77,70 & 65,38 & 61,10 & 72,48 & 70,29 \\
2017 & 77,99 & 64,79 & 60,31 & 73,56 & 70,30 \\
2018 & 79,11 & 67,49 & 60,51 & 77,32 & 72,74 \\
\hline
\end{tabular}

Ket: PPS=Pilar Pembangunan Sosial; PPE=Pilar Pembangunan Ekonomi; PPL=Pilar Pembangunan Lingkungan; PPHTK=Pilar Pembangunan Hukum \& Tata Kelola

Tabel 5

Nilai Indeks Stunting Provinsi Berdasarkan Kategori

\begin{tabular}{|c|c|c|c|c|c|c|c|c|}
\hline \multirow[b]{2}{*}{ Kategori } & \multicolumn{2}{|c|}{ Tahun 2015} & \multicolumn{2}{|c|}{ Tahun 2016} & \multicolumn{2}{|c|}{ Tahun 2017} & \multicolumn{2}{|c|}{ Tahun 2018} \\
\hline & Provinsi & $\begin{array}{l}\text { Nilai } \\
\mathcal{J} \mathcal{S}\end{array}$ & Provinsi & $\begin{array}{l}\text { Nilai } \\
\mathcal{J} \mathcal{S}\end{array}$ & Provinsi & $\begin{array}{l}\text { Nilai } \\
\mathcal{J} \mathcal{S}\end{array}$ & Provinsi & $\begin{array}{l}\text { Nilai } \\
\mathcal{J} \mathcal{S}\end{array}$ \\
\hline \multirow[t]{9}{*}{ Rendah } & Papua & 13,48 & Papua & 14,46 & Papua & 9,93 & Papua & 14,07 \\
\hline & Papua Barat & 35,70 & NTT & 37,19 & NTT & 42,92 & NTT & 50,25 \\
\hline & NTT & 36,61 & Kaltara & 47,48 & Papua Barat & 43,18 & Papua Barat & 52,78 \\
\hline & Kaltara & 52,00 & Papua Barat & 48,46 & Maluku & 51,05 & Maluku Utara & 54,24 \\
\hline & Maluku & 52,15 & Maluku & 50,07 & Kaltara & 54,30 & Maluku & 56,02 \\
\hline & Maluku Utara & 54,04 & Maluku Utara & 54,58 & Maluku Utara & 55,96 & Kalbar & 63,32 \\
\hline & Sulbar & 59,64 & Sulbar & 59,73 & Riau & 60,94 & Kalteng & 65,17 \\
\hline & Kalteng & 61,51 & Bengkulu & 62,59 & Kalbar & 61,95 & Aceh & 65,81 \\
\hline & Kalbar & 63,49 & & & Sulbar & 62,19 & & \\
\hline \multirow[t]{19}{*}{ Sedang } & Aceh & 63,89 & Gorontalo & 62,76 & Bengkulu & 64,30 & Bengkulu & 66,23 \\
\hline & Bengkulu & 63,94 & Aceh & 63,73 & Aceh & 65,18 & Riau & 66,63 \\
\hline & Sulteng & 64,49 & Kalbar & 63,91 & NTB & 66,21 & Lampung & 66,77 \\
\hline & Sumbar & 66,52 & Sulteng & 64,53 & Kalteng & 66,56 & Sulbar & 67,22 \\
\hline & Gorontalo & 66,61 & Sumbar & 65,32 & Sumbar & 66,90 & Sumbar & 68,99 \\
\hline & Sulut & 66,87 & Kalteng & 65,49 & Lampung & 68,86 & Sulteng & 69,72 \\
\hline & Riau & 67,00 & Riau & 65,53 & Sulteng & 69,06 & Jawa Barat & 70,07 \\
\hline & Sumut & 68,66 & Sumut & 66,51 & Sumut & 69,07 & Kalsel & 70,52 \\
\hline & Sultra & 68,82 & Indonesia & 70,29 & Gorontalo & 69,14 & Kaltara & 71,17 \\
\hline & Lampung & 69,54 & Lampung & 70,34 & Indonesia & 70,30 & Banten & 71,62 \\
\hline & Indonesia & 69,77 & Kaltim & 70,45 & Sultra & 71,42 & Sumsel & 72,70 \\
\hline & Jawa Barat & 70,04 & Sultra & 70,64 & Banten & 72,00 & Indonesia & 72,74 \\
\hline & Banten & 71,53 & Sulut & 71,63 & Jawa Barat & 73,09 & Sumut & 72,98 \\
\hline & Kalsel & 72,23 & Jawa Barat & 72,45 & Sumsel & 73,10 & Jawa Timur & 73,35 \\
\hline & Kaltim & 73,45 & Sumsel & 72,81 & Sulut & 74,09 & NTB & 73,94 \\
\hline & Jambi & 75,00 & Jambi & 73,91 & Jambi & 74,41 & Gorontalo & 75,70 \\
\hline & NTB & 75,24 & Kalsel & 74,37 & Kep, Riau & 74,79 & Sultra & 75,71 \\
\hline & Sumsel & 75,26 & Banten & 75,35 & & & Jambi & 76,26 \\
\hline & & & NTB & 75,83 & & & Kep, Riau & 77,26 \\
\hline \multirow[t]{8}{*}{ Tinggi } & Jawa Tengah & 76,76 & Kep. Babel & 77,84 & Kaltim & 74,83 & Jawa Tengah & 78,02 \\
\hline & Sulsel & 76,80 & Sulsel & 78,01 & Jawa Timur & 74,91 & Kep. Babel & 78,35 \\
\hline & Jawa Timur & 78,16 & Jawa Timur & 78,22 & Kalsel & 75,10 & Kaltim & 78,45 \\
\hline & Kep, Babel & 78,43 & Jawa Tengah & 78,88 & Kep. Babel & 76,86 & Sulut & 79,58 \\
\hline & Kep, Riau & 81,84 & Kep, Riau & 79,32 & Sulsel & 78,13 & Sulsel & 81,27 \\
\hline & Yogyakarta & 86,72 & Yogyakarta & 89,06 & Jawa Tengah & 79,32 & Jakarta & 83,94 \\
\hline & Jakarta & 87,60 & Jakarta & 89,22 & Yogyakarta & 81,70 & Yogyakarta & 84,18 \\
\hline & Bali & 89,13 & Bali & 90,87 & $\begin{array}{l}\text { Jakarta } \\
\text { Bali }\end{array}$ & $\begin{array}{l}86,68 \\
88,35\end{array}$ & Bali & 90,41 \\
\hline
\end{tabular}


Tabel 6

Analisis Korelasi Nilai $\mathcal{J} \mathcal{S}$ dengan Prevalensi Stunting Tahun 2018

\begin{tabular}{ccc}
\hline Nilai indeks & $r$ & $\rho$ value \\
\hline Nilai IS 2015 & $-0,479$ & $0,004^{*}$ \\
Nilai IS 2016 & $-0,510$ & $0,002^{*}$ \\
Nilai IS 2017 & $-0,433$ & $0,009^{*}$ \\
Nilai IS 2018 & $-0,446$ & $0,007^{*}$ \\
\hline
\end{tabular}

Ket: ${ }^{*}$ signifikan pada $a<0,01$

\section{BAHASAN}

Hasil penelitian ini menunjukkan pencapaian $\mathcal{J} \mathcal{S}$ komposit di Indonesia selama retang tahun 2015 - 2018 berada pada kategori sedang. Kondisi tersebut masih belum bisa dikatakan baik ditinjau dari ukuran ini karena selama 4 tahun tersebut Indonesia belum dapat mencapai kategori tinggi sekalipun (Tabel 5). Dimensi pada pilar pembangunan lingkungan masih memiliki nilai $\mathcal{J} \mathcal{S}$ dimensi yang paling rendah (pencapaian $\mathcal{J} \mathcal{S}$ dimensi dapat dilihat pada Tabel 4). Nilai pada dimensi tersebut perlu diperbaiki untuk meningkatkan $\mathcal{J} \mathcal{S}$ komposit Indonesia. Ada 2 variabel yang berada pada dimensi tersebut yaitu rumah tangga yang memiliki akses terhadap air dan sanitasi yang layak.

Hasil penelitian ini sejalan dengan penelitia yang menunjukkan bahwa peningkatan cakupan rumah tangga yang memiliki akses terhadap layanan sanitasi yang layak merupakan prediktor terkuat $(\beta=-0,876)$ dalam menentukan penurunan stunting pada balita di Indonesia. ${ }^{17}$ Penelitian lain yang sama juga menyatakan bahwa peluang balita mengalami stunting karena sanitasi yang kurang baik 4 kali lebih besar dibanding dengan sanitasi lingkungan baik. ${ }^{18}$ Hasil penelitian ini sekaligus mengkonfirmasi penelitian sebelumnya di Indonesia bahwa fasilitas sanitasi dan pengolahan air rumah tangga berpengaruh terhadap stunting. Rumah tangga yang tidak memiliki jamban memiliki prevalensi stunting sebesar 35,3 persen dibandingkan sebaliknya $(24,0 \%)$. Rumah tangga yang Cuci Tangan Pakai Sabun (CTPS) memiliki prevalensi stunting sebesar 25,8 persen dibandingkan tidak CTPS (31,6\%). Ketiadaan fasilitas sanitasi juga mendorong perilaku tidak mencuci tangan dengan benar setelah buang air dan menyiapkan serta pemberian makanan anak. ${ }^{19}$

Perbaikan melalui intervensi terhadap dimensi pilar pembangunan lingkungan ini diperlukan untuk memperbaiki nilai IS komposit di Indonesia. Penelitian di India menunjukkan intervensi sanitasi terhadap komunitas yang berdomisili pada lingkungan dengan kondisi kesehatan buruk dan rentan berpengaruh sebesar $0,7 \mathrm{~cm}$ terhadap tinggi badan setelan anak berusia 4 tahun. ${ }^{20}$ Ketiadaan fasilitas sanitasi yang layak juga meningkatan kasus penyakit bersumber kontaminan bakteri seperti diare dan kecacingan ${ }^{21}$ yang selanjutnya berpengaruh pada status gizi anak. Hasil Riskesdas pada tahun 2018 saja mencatat peningkatan kasus diare pada balita sebesar 18,5 persen dibandingkan tahun 2013 $(12,3 \%)^{10}$. Penelitian di Ethiopia menunjukkan lebih lanjut bahwa integrasi WASH (Water, Sanitation and Hygine) dengan program perbaikan gizi mampu menurunkan stunting dibandingkan dengan hanya program gizi saja. ${ }^{22}$ Penelitian ini menegaskan WASH memiliki potensi sebagai komponen penting dari strategi komprehensif penurunan stunting. ${ }^{23}$

Nilai $\mathcal{J} \mathcal{S}$ masing-masing provinsi (Tabel 5) menempatkan provinsi Papua, Papua Barat, Maluku, Maluku Utara, Nusa Tenggara Timur, dan Kalimantan Barat setiap tahun berturut-turut berada dalam kelompok daerah dengan nilai $\mathcal{J} \mathcal{S}$ kategori rendah. Provinsi-provinsi tersebut dikelompokkan sebagai daerah dengan potensi terjadinya kasus stunting yang tinggi. Kalimantan Utara dan Sulawesi Barat juga merupakan provinsi yang cenderung memiliki nilai $\mathcal{J S}$ rendah sebelum tahun 2018. Papua, Papua Barat dan Nusa Tenggara Timur bahkan selalu menduduki posisi indeks yang paling rendah. Ketiga daerah ini sudah dikenal sebagai provinsi yang masih tertinggal sehingga sudah 
seharusnya mendapatkan perhatian lebih dan serius dalam penanggulangan stunting. Sebagian besar provinsi yang berada dalam kategori rendah ini juga secara geografis terletak di bagian timur Indonesia dan merupakan daerah pemekaran kecuali provinsi Bengkulu, Riau dan Aceh. Peningkatan atau perbaikan kondisi hampir seluruh aspek dimensi diperlukan untuk memperbaiki nilai $\mathcal{J} \mathcal{S}$ provinsi tersebut.

Bali, Yogyakarta dan Jakarta merupakan kelompok provinsi dengan $\mathcal{J} \mathcal{S}$ paling tinggi setiap tahun disusul oleh Jawa Tengah dan Jawa Timur. Hal ini dapat dimaklumi mengingat selama ini wilayah yang berada di Pulau Jawa dan Bali merupakan daerah orientasi pembangunan. Namun demikian, ada dua provinsi di luar Pulau Jawa dan Bali yaitu Sulawesi Selatan dan Kepulauan Bangka Belitung juga berturut-turut masuk dalam daerah dengan kategori $\mathcal{J} \mathcal{S}$ tinggi. Hal ini masih dimungkinkan karena Pulau Sumatera dan Sulawesi merupakan daerah orientasi pembangunan setelah Jawa dan Bali. Kedua daerah ini juga mempunyai nilai $\mathcal{J} \mathcal{S}$ dimensi pada pilar pembangunan ekonomi yang cukup baik dibandingkan provinsi yang berada pada kategori dibawahnya. Nilai $\mathcal{J} \mathcal{S}$ pada dimensi pilar pembangunan sosial yang didalamnya terdiri dari variabel seperti ASI eksklusif dan asupan energi dan zat gizi secara umum pada skala penelitian yang lebih luas diakui sebagai determinan stunting. Pada penelitian ini tidak demikian adanya karena pemodelan longitudinal dan pertumbuhan hampir tidak dimungkinkan dengan data agregat. ${ }^{24}$

Indeks stunting sebagai alat ukur baru dapat divalidasi menggunakan validitas konkuren dengan cara menghitung korelasi indeks tersebut dengan ukuran yang menjadi kriteria, yakni ukuran eksternal yang telah dianggap valid. ${ }^{25}$ Korelasi yang signifikan nilai $\mathcal{J S}$ dengan prevalensi stunting pada penelitian ini menunjukkan hubungan cukup kuat dan arah negatif (Tabel 6). Nilai validasi dan kemaknaan tertinggi pada tahun 2017 menujukkan bahwa penurunan stunting terjadi dalam rentang waktu minimal 2 tahun setelah dilakukan pengalokasian pembiayaan program intervensi stunting. ${ }^{26}$ Hubungan arah negatif menjelaskan kecenderungan semakin tinggi nilai $\mathcal{J} \mathcal{S}$ maka semakin rendah prevalensi stunting wilayah tersebut.

Hasil ini sekaligus memungkinkan $\mathcal{J} \mathcal{S}$ merupakan ukuran yang valid digunakan di Indonesia meskipun penafsiran secara hati-hati tetap diperlukan karena tidak ada indeks komposit yang berlaku secara universal. Luas dan keberagaman wilayah Indonesia serta keterbatasan penyediaan data merupakan keterbatasan lain dari kontruksi indeks ini sehingga perlu dipertimbangkan penyusunan indek dalam cakupan wilayah yang lebih kecil. Kondisi ini juga selanjutnya menjadi keterbatasan penelitian ini mengingat analisis data agregat hanya dilakukan pada jumlah provinsi yang relaif kecil yaitu $n=34$. Hasil penelitian ini tetap memiliki potensi penerapan yang luas dan penggunaannya secara substansial membantu pengambilan keputusan dalam kebijakan publik karena ketersediaan data dan kerahasiaan individu tidak diperlukan dalam analisis data agregat. Penelitian ini hanya memberikan penekanan rekomendasi perbaikan pada variabel dimensi pilar pembangunan lingkungan dan ekonomi terlebih dulu karena variabel pada dimensi lainnya akan memperberat masalah stunting.

\section{SIMPULAN DAN SARAN}

\section{Simpulan}

Berdasarkan penelitian ini maka dapat disimpulkan bahwa model $\mathcal{J} \mathcal{S}$ merupakan ukuran evaluasi yang responsif terhadap intervensi stunting pada balita ( $0-56$ bulan) di Indonesia. Indeks stunting komposit secara nasional pada rentang tahun 2015 - 2018 mengalami peningkatan dan perbaikan meskipun berada pada kategori sedang.

\section{Saran}

Terkait hasil penelitian ini maka disarankan untuk mempertimbangkan upaya peningkatan pencapaian seluruh nilai indeks pada setiap dimensi pilar pembangunan dengan penekanan pada dimensi pilar pembangunan lingkungan dan ekonomi. Perhatian juga seharusnya lebih difokuskan pada wilayah timur Indonesia dan provinsi baru hasil pemekaran wilayah. 


\section{UCAPAN TERIMA KASIH}

Penulis menyampaikan terimakasih kepada Kementerian Kesehatan RI melalui Badan PPSDM Kesehatan yang telah memberikan dukungan pembiayaan penelitian.

\section{RUJUKAN}

1. Perkins JM, Kim R, Krishna A, McGovern $M$, Aguayo VM, Subramanian $S \mathrm{~V}$. Understanding the association between stunting and child development in low- and middle-income countries: Next steps for research and intervention. Soc Sci Med. 2017;193:101-9.

2. Sudfeld CR, McCoy DC, Danaei G, Fink G, Ezzati M, Andrews KG, et al. Linear growth and child development in low- and middleincome countries: A meta-analysis. Pediatrics. 2015;135(5):e1266-75.

3. de Onis M, Branca F. Childhood stunting: A global perspective. Matern Child Nutr. 2016;12:12-26.

4. Black RE, Allen LH, Bhutta ZA, Caulfield LE, de Onis M, Ezzati M, et al. Maternal and child undernutrition: global and regional exposures and health consequences. Lancet. 2008;371(9608):243-60.

5. Adair LS, Fall CHD, Osmond C, Stein AD, Martorell R, Ramirez-Zea $M$, et al. Associations of linear growth and relative weight gain during early life with adult health and human capital in countries of low and middle income: Findings from five birth cohort studies. Lancet. 2013;382(9891):525-34.

6. Hoddinott J, Alderman $\mathrm{H}$, Behrman JR, Haddad L, Horton S. The economic rationale for investing in stunting reduction. Matern Child Nutr. 2013;9(S2):69-82.

7. Development Initiatives. 2020 Global nutrition report: Action on equity to end malnutrition. The Global Nutrition Report's Independent Expert Group. Bristol, UK; 2020. 168 hal.

8. Galasso E, Wagstaff A. The Economic Costs of Stunting and How to Reduce Them. World Bank Gr Policy Res Note. 2016;1-57.

9. Balitbangkes Kemenkes RI. Riset Kesehatan Dasar: Riskesdas 2013.
Jakarta: Balitbangkes Kemenkes Rl; 2013.

10. Balitbangkes Kemenkes RI. Hasil Utama Riskesdas 2018. Jakarta; 2018.

11. Renyoet BS, Martianto D, Sukandar D. Potensi Kerugian Ekonomi Karena Stunting Pada Balita Di Indonesia Tahun 2013. J Gizi dan Pangan. 2016;11(3):24754.

12. Tim Nasional Percepatan Penanggulangan Kemiskinan. Strategi Nasional Percepatan Pencegahan Stunting Periode 2018 2024. Jakarta: TNP2K; 2018. 86 hal.

13. Bappenas RI. Ringkasan Metadata Tujuan Pembangunan Berkelanjutan (TPB)/ Indikator Sustainable Development Goals (SDGS) Indonesia. Kementerian PPN I Bappenas. Jakarta; 2017. 106 hal.

14. Beal T, Tumilowicz A, Sutrisna A, Izwardy $D$, Neufeld LM. A review of child stunting determinants in Indonesia. Matern Child Nutr. 2018;14(4):1-10.

15. Sassi M. Understanding Food Insecurity. Understanding Food Insecurity. 2018.

16. Badan Pusat Statistik. Penyempurnaan Penyusunan Indeks Pembangunan Regional. Jakarta: Badan Pusat Statistik; 2010. 146 hal.

17. Wardani Z, Sukandar D, Baliwati YF, Riyadi H. Akses Sanitasi, Merokok dan Annual Parasite Incidence Malaria sebagai Prediktor Stunting Baduta di Indonesia. Media Kesehat Masy Indones. 2020;16(1):127.

18. Cahyono F, Manongga SP, Picauly I. Faktor Penentu Stunting Anak Balita Pada Berbagai Zona Ekosistem Di Kabupaten Kupang. J Gizi dan Pangan. 2016;11(1):918.

19. Torlesse H, Cronin AA, Sebayang SK, Nandy R. Determinants of stunting in Indonesian children: Evidence from a cross-sectional survey indicate a prominent role for the water, sanitation and hygiene sector in stunting reduction. BMC Public Health. 2016;16(1):1-11.

20. Augsburg B, Rodríguez-Lesmes PA. Sanitation and child health in India. World Dev. 2018;107:22-39.

21. Freeman MC, Garn J V., Sclar GD, Boisson S, Medlicott K, Alexander KT, et al. The impact of sanitation on infectious disease and nutritional status: A systematic review and meta-analysis. Int $\mathrm{J}$ 
Hyg Environ Health. 2017;220(6):928-49.

22. Head JR, Pachón $H$, Tadesse W, Tesfamariam M, Freeman MC. Integration of water, sanitation, hygiene and nutrition programming is associated with lower prevalence of child stunting and fever in Oromia, Ethiopia. African J Food, Agric Nutr Dev. 2019;19(4):14971-93.

23. Cumming $\mathrm{O}$, Cairncross $\mathrm{S}$. Can water, sanitation and hygiene help eliminate stunting? Current evidence and policy implications. Matern Child Nutr.
2016;12:91-105.

24. Azwar S. Reliabilitas dan Validitas. 4 ed. Yogyakarta: Pustaka Pelajar; 2013. 181 hal.

25. Jacob R. Using Aggregate Administrative Data in Social Policy Research. Washington DC; 2016.

26. Mary S, Saravia-Matus S, Gomez y Paloma S. Does nutrition-sensitive aid reduce the prevalence of undernourishment? Food Policy. 2018;74(March 2017):100-16. 